\title{
1 Study of Biomass Combustion Wastes
}

2 Roberto García, Consuelo Pizarro*, Ana Álvarez, Antonio G. Lavín, Julio L. Bueno

3 Department of Chemical and Environmental Engineering. Faculty of Chemistry.

4 University of Oviedo. Julián Clavería s/n. 33006. Oviedo. Spain

5 DOI: $10.1016 /$ j.fuel.2015.01.079

$6 \quad *$ corresponding author telephone: +34985103438 fax: +34 985103434

9 e-mail: pizarroconsuelo@uniovi.es

11 Abstract

12 A number of widely referenced environmental and logistic advantages suggest biomass as an interesting feedstock to obtain energy in large quantities. One of the most important problems when using biomass is the amount of solid wastes produced, which causes deposition and corrosion phenomena (slagging and fouling) entailing energy efficiency decrement and maintenance problems.

This work focuses on the study of ashes from eighteen different biomass samples, including energy crops, agricultural, industrial and forestry wastes and commercial fuels.

Morphology (SEM) and grain size (PSD-LD) studies showed a homogeneous structure with low quantities of health risky fine particles for most samples after $550^{\circ} \mathrm{C}$ burning. Compositional studies (EDXA, XRF) suggested that some of the studied samples, such as almond shell or rice husk, may respectively present high deposition and corrosion risks. 
27 Biomass ash, ternary diagrams, XRF, SEM, particle size distribution, TGA

\section{Introduction}

Constant growth in mankind's energy requirements over the last century in addition to the high dependence on fossil fuels has outlined important environmental challenges. In this scenario, renewable energy sources appear to be a sustainable tool to complement and gradually substitute fossil fuels in energy production. Among them, biomass, regarded as a feedstock for thermal conversion, presents some advantages such as its neutrality concerning $\mathrm{CO}_{2}$ emissions during its life cycle [1] or its low $\mathrm{N}$ and $\mathrm{S}$ content that entails low $\mathrm{NO}_{\mathrm{x}}$ and $\mathrm{SO}_{2}$ emissions [2]. Besides this, biomass is considered as an autonomous resource which partially avoids foreign energy dependence [3]. Because of the advantages when using biomass for energy production, it has experienced a huge development in recent years.Nevertheless, it also presents some disadvantages, being one of the most important the generation of solid wastes [4]. Ash presence is highly negative for the combustion process as it involves energy efficiency losses and higher maintenance expenses due to unburnts and depositions (slagging and fouling) that cause thermal resistances in heat exchangers, corrosion phenomena and the increase of fumes and aerosol emissions $[5,6]$.

Ashes generated during the biomass combustion may present a variable composition with a wide range of mineral and inorganic components included in its structure. These can proceed from the vegetal biomass itself or from other contaminants added during pre-treatment or transport phases. Because of this, any quality control criterion suggests the exhaustive knowledge of ash characteristics, both morphological and compositional. 
To that aim, there are several analytical techniques available, commonly used by several authors that supply complete information about biomass samples. In that way Scanning Electron Microscopy (SEM) coupled to an Energy Dispersive X-Ray Analyzer (EDXA) allows simultaneous morphological and semi-quantitative compositional information of the studied sample. Biagini [7] and Umamaheswaran [8] use these techniques to study the structural variations of some biomass fuel after combustion processes. Xiao [9] evaluates the structural evolution of biomass ashes after different ashing temperatures. Nortey Yeboah [10] characterizes coal ashes with high carbon content that will be later co-fired with biomass. Carrasco [11] uses SEM to characterize bottom ash from biomass to use in concrete formulation and Abraham [12] studies several ash samples trying to find reuse for them in fertilizer, cement or pollutant adsorbent industries. Wang S. [13] employs EDXA to obtain the elemental composition of biomass fly ash.

Sample's morphology and grain size information can be obtained by developing Particle size distribution (PSD). Bridgeman [14] and Mediavilla [15] sieved and weighted fractions of biomass fuels to study the effect of raw materials size on combustion properties and kinetic parameters, respectively. Becidan [16] determined fly ash grain distribution, by previously dividing them in size cuts using an Electrical Low Pressure Impactor. Roy [17] studied particle size distributions of biomass samples by direct measure on SEM images and Wang G. [18] did the same to fly ashes by laser diffraction (LD).

To obtain chemical composition data other techniques besides EDXA can be used. One of the most common is X-Ray Fluorescence (XRF). Reviews fromVassilev [19, 20] provide plenty of information about the elementary composition of several biomass samples. Some other authors also use this technique to study the biomass-ash deposition 
tendency of different ashes by using predictive coefficients $[21,22]$ or ternary diagrams $[23,24]$.

Thermo Gravimetrical Analysis (TGA) is used by several authors to thermally analyze different biomass samples and determine characteristic points in their burning profiles such as their ignition point, peak temperature, burn out temperature $[25,26]$ or kinetic parameters [27]. Our research group has recently proposed a mechanism to obtain proximate analysis data by using this analytical tool [28].

This work focuses on obtaining ash behaviour data of several different biomass samples and comparing them in order to determine which ones would be most suitable for use in further combustion processes.

\section{Materials and methods}

\subsection{Samples}

In this work, eighteen different biomass samples were tested after air dried and grinded to assure homogeneity. They were chosen as represent all the classification groups, e.g. as these suggested by Ávila [29]. Energy crops (sorghum -S- and thistle-THI-), agricultural feedstocks (beetroot pellets - BP-, straw pellets - SP- and rice husk - $\mathrm{RH}-$,), industrial sources (almond shell -AS-, coffee husk - $\mathrm{CH}$-, olive stone -OS-, pine kernel shell -PKS- and vine orujillo -VO-) and forestry wastes (olive tree pruning -OTP-, pine apple leaf -PL-, and vine shoot chips -VSC-). In addition to this some of the most common commercial fuels currently available at the Spanish market were studied (briquette-BRI-, charcoal-CC-, pine and pine apple leaf pellets -PPLP-, wood chips WC- and wood pellets -WP-)

General combustion-data for these samples is provided in Table 1. Their ashes obtained at $550^{\circ} \mathrm{C}$ were also studied. This temperature was chosen as it is considered by several 
authors $[30,31,32]$ to be the optimum one to determine their properties. Proximate and ultimate analysis data and higher heating values (HHV) are summarized from previous works by this research group [33].

\subsection{Experimental equipment}

SEM images were obtained, in this work, using a MEB JEOL-6100 equipment coupled to an INCA Energy 200 EDX analyser, to simultaneously obtain 3D images and semiquantitative elemental analyses. To this aim samples were previously air dried and grinded under $500 \mu \mathrm{m}$ and covered with a thin gold layer, as they must be conductant.

Particle size distribution was developed with a laser diffractometer Malvern grinded to avoid coalescence, and measure real particle size

XRF data was obtained using Phillips PW2404 equipment joined to a PW2540 automatic sample loader. Samples ashes were obtained at $550^{\circ} \mathrm{C}$ and later burnt at $900^{\circ} \mathrm{C}$ in order to obtain the mineral matter. Nine elements data $(\mathrm{Si}, \mathrm{Al}, \mathrm{Fe}, \mathrm{Mn}, \mathrm{Mg}$,

$\mathrm{Ca}, \mathrm{Na}, \mathrm{K}, \mathrm{Ti}$ and P) were obtained, considered as oxides in its highest oxidation level. TGA experiments were developed in a Perkin Elmer STA 6000 thermobalance, using $10 \mathrm{mg}$ of sample and a slow heating rate $\left(5^{\circ} \mathrm{C} / \mathrm{min}\right)$ from room temperature up to $900^{\circ} \mathrm{C}$ in an oxidant air-atmosphere with an air flow of $40 \mathrm{ml} / \mathrm{min}$.

\section{Theory and calculation}

Slagging and fouling are two phenomena, directly related to deposition and corrosion, commonly observed when operating a biomass-powered combustion system. The first of them is produced at high temperature zones, mainly on grills or chamber walls, whilst the second istypical of low temperature zones, like the heat exchanger surfaces. They depend on the fuel's chemical composition, conversion technology used and operating conditions [19]. 
$\mathrm{XRF}$ data is a useful tool to calculate some deposition-predictive indexes, some of which are included in Table 2, as this phenomenon is usually increased by high concentrations of low melting point elements, like $\mathrm{Na}, \mathrm{K}, \mathrm{S}, \mathrm{Cl}$ (alkali sulphates or chlorides) and decreased by high melting point ones such as $\mathrm{Ca}, \mathrm{Mg}$ or $\mathrm{S}$ (calcium or magnesium silicates).

\section{Results and discussion}

\subsection{Morphology and size}

Due to space requirements, only the SEM images that show the most relevant facts are included in this work. In this way a yellow marked fibrous structure can be observed in the wood chips sample (figure 1). This is due to the high lignin levels of woody fuels which make them harder and more difficult to grind homogenously. Structural holes (blue) that confer this fuel a high specific surface but low density, are also detected. On the other hand, harder samples such as pine kernel shell (Figure 2a) present, before burning, isolated particles of high size and quite regular sphere-shape. Those two effects co-exist in the pine and pine apple leaf pellets sample (Figure $2 b$ and $2 c$ ) which is a mix between a woody fuel and a harder one. Images observed after $550^{\circ} \mathrm{C}$ treatment changes due to thermal effect are easily seen. At this point structural chemical bonding has been broken so hemicellulose, cellulose and lignin of most biomass samples have turned into gaseous $\mathrm{CO}_{2}$ and $\mathrm{CH}_{4}$ having lost up to $70 \%$ of their initial weight, giving a finely divided structure. Some particles are outlined (orange) in this structure are unburnts, formed by alkali sulphates with high melting points not vaporized at low temperatures that gain relative weight at high temperatures.Low melting point elements may also agglomerate forming particle clusters and high melting temperature compounds.

Concerning particle size distribution, ash particles can be classified in thin or thick if they, respectively, cross or do not cross a $400 \mu \mathrm{m}$ mesh sieve [11]. Fly ash is usually 
considered to have a diameter between 0.2 and $200 \mu \mathrm{m}$ and bottom ash as between 200 and $1000 \mu \mathrm{m}$ [35]. The concept PM10 (particulate matter 10) meansthe quantity of particles under $10 \mu \mathrm{m}$ that float in the atmosphere polluting its composition. This group includes the PM2.5 (particulate matter $2.5 \mu \mathrm{m}$ ) ones, or breathable particles, that can affect human health by penetrating human airways. In this work, PSD results obtained by laser diffraction, are divided in five ranges (under 10, 10-100, 100-200, 200-400 and over $400 \mu \mathrm{m}$ ) and their results compared. It is interesting for ashes to have as higher thick or bottom ash fractions as possible (more than $200 \mu \mathrm{m}$ particles) that are easily removed from the bottom of the chambers, avoiding contamination and health damage risks. As can be seen in Figure 3 most of the studied samples have more than $80 \%$ of ash particles thicker than $200 \mu \mathrm{m}$, beetroot pellets, pine and pine-apple pine pellets or vine orujillo more than $90 \%$ of them. On the other hand wood pellets and almond shell were found to have, respectively, 35 and $45 \%$ of particles under fly ash considered diameter. None of the samples presented PM10 values over 3\% and PM2.5 detected values were negligible in every case, with only charcoal and pine kernel shell samples reaching $0.1 \%$.

\subsection{Chemical composition}

Figure 4 presents the results obtained for EDXA analysis after $550{ }^{\circ} \mathrm{C}$ ashing temperature as an average of six measure points throughout SEM-observed sample. As can be seen in Table 1, raw fuel structure is, as expected, basically organicwith a vast majority of $\mathrm{C}$ and $\mathrm{O}$ in the sample composition and a $\mathrm{C} / \mathrm{O}$ ratio between 0.8 and 1 in most caseswhich is influential in biomass reactivity and indicates higher heating value.Beetroot pellets, sorghum and vine shoot chips present a ratio slightly lower,close to 0.7 and rice husk far under this value with a 0.38 ratio, being a highly oxygenated structure that confers low HHV to this fuel. On the other hand charcoal presents a 
4.68C/O ratio, as it underwent a previous pyrolysis. When these data are compared with the ones obtained after $550^{\circ} \mathrm{C}$ burning (Figure 4), it can be highlighted that at this temperature most of the carbon structure was eliminated and the proportion of high melting-temperature elements has increased. C values are commonly between $15-25 \%$ while $\mathrm{O}$ (which still remains in oxides) carbonates or sulphates has slightly increased until 40-60\%. Charcoal differs from these results due to the previously explained reasons. Concerning other elements it is remarkable the high silicon peaks observed in charcoal (40\%), pine kernel shell or straw pellets (10\%). K and Ca, key elements in fouling and slagging generation, are also interesting being the first ones close to $5 \%$ in most samples, with the exception of straw pellets (10\%), charcoal (15\%), pine and pine apple leaf pellets (20\%) or vine orujillo (30\%). Ca values are slightly above K ones, with olive stone, wood or beetroot pellets (10\%) and charcoal (30\%) above the average. $\mathrm{Mg}$ presents a nearly constant value of 3-5\% for most samples and the low Na values (around 1 are the other remarkable notes. $\mathrm{Cl}$ values detected in the rice husk sample are extremely high, reaching $30 \%$, this may proceed from fertilizers or a bad homogeneity of measure points, but there are some herbaceous species with high natural values in themselves.

X-Ray fluorescence measured values are presented in Table 3. These are used to calculate deposition predictive equations and their results compared with ternary diagrams and experimental experience. Every predictive equation proposed in Table 3 was calculated and meaningful differences were noticed for the same sample. Due to this, only the most referenced equations are proposed and compared in this work, one to predict slag $\left(\mathrm{R}_{\mathrm{b} / \mathrm{a}}\right)$ and one to predict fouling $\left(\mathrm{F}_{\mathrm{u}}\right)$, but both can be used to predict general deposition and their results compared. These results are presented in Table 3 following a colour criterion, red, orange and green being high, medium and low 
deposition risk respectively. As can be seen deposition predictions obtained from both equations agree in the samples with high and low values but present some contradictions in the intermediate ones, conceding high or medium deposition risk in some cases depending on the considered equation. When these results are compared with the ones obtained by using ternary diagrams this tendency can be confirmed. In this way when a sample presents more than $50 \%$ (mass percentage in ashes) of $\mathrm{CaO}$ or $\mathrm{SiO}_{2}$ combined with more than $15 \%$ of $\mathrm{K}_{2} \mathrm{O}$, its ashes can easily agglomerate and therefore deposit. This means the samples on the right of the red line drawn on the $\mathrm{SiO}_{2}-\mathrm{CaO}-\mathrm{K}_{2} \mathrm{O}$ diagram (Figure 5). As can be determined,samples AS, CC, PPLP, PL, PKS, VO and WP present high deposition risks, all of them were considered as high or medium risk by using predictive equations. Some contradictions are also noticed, for example fuels with the highest deposition predictive values like VSC, THI or $\mathrm{CH}$ are not supposed to present high risk according to this diagram.

The $\mathrm{SiO}_{2}+\mathrm{Al}_{2} \mathrm{O}_{3}+\mathrm{Fe}_{2} \mathrm{O}_{3}-+\mathrm{Na}_{2} \mathrm{O}+\mathrm{TiO}_{2}-\mathrm{CaO}+\mathrm{MgO}+\mathrm{MnO}-\mathrm{K}_{2} \mathrm{O}+\mathrm{P}_{2} \mathrm{O}_{5}+\mathrm{S}$ (Figure 6) diagram is also presented. This classifies samples according to their acidity (high, medium or low) which is influential oncorrosion phenomena and melting point ( $\mathrm{S}, \mathrm{C}, \mathrm{K}$ and $\mathrm{CK}$ types). $\mathrm{S}$ and $\mathrm{K}$ types present high deposition risks due to silicates formation and potassium presence. $\mathrm{C}$ type is expected to have high melting temperature (and therefore, low depositions) due to high Ca levels. CK type is an intermediate between $\mathrm{C}$ and $\mathrm{K}$. According to this, results are quite homogeneous if compared with $\mathrm{SiO}_{2}-\mathrm{CaO}-$ $\mathrm{K}_{2} \mathrm{O}$ diagram ones, as they both consider PPLP, PL, PKS, SP and VO as high deposition risk samples and AS and WP as medium risk ones. The same contradictions with predictive equations as in the previous case are noticed.

When compared with experimental experience, it should be stated that most of the samples except PKS, VO and WP presented no deposition problems when burning on a 
crucible. These samples are predicted as high deposition risk with both graphic methods, so they must be considered, for our tested samples, as more reliable. Regarding acidity, following the explained criterion only $\mathrm{RH}$ presents high acidity values, meaning high corrosion risk in the burning equipment, which agrees with high chlorine values measured by EDXA.

\subsection{Thermogravimetric study}

As previously stated, thermogravimetry is a versatile tool that can be used in several ways to study biomass and its wastes. One of the most common uses for the burning profile of a sample, that relates weight loss and temperature, is to determine characteristic points: ignition point, when a fuel begins to react, and peak point, when mass loss speed is the highest in the sample, related with its reactivity. Table 4 shows the characteristic points obtained for the selected samples. In this work, TGA is also use to compare different biomass samples char and ash thermal behaviour; this means when fuel's weight attains a steady speed after peak temperature, and before the reaction end, from 400 to $850^{\circ} \mathrm{C}$.

As can be seen ignition temperature is in the range $170-200{ }^{\circ} \mathrm{C}$ for every sample except THI,that falls $130^{\circ} \mathrm{C}$,entailing higher auto-ignition risk if appropriate conditions, like high powdery atmospheres, are reached, and WC and CC that increase until 212 and $233^{\circ} \mathrm{C}$, respectively.

Peak temperature values, when a sudden volatile matter and a huge mass loss occur, are usually between $230-330^{\circ} \mathrm{C}$. CC, because of its pyrolytic origin, presents a lower volatile matter quantity, and a more constant mass loss, this value increasing up to $487^{\circ} \mathrm{C}$.

Figures 7 and 8 show the mass loss of the studied sample's from 400 to $850{ }^{\circ} \mathrm{C}$. As can be seen, every sample (except VO and CC) has lost more than $60 \%$ of its original 
weight at this relatively low temperature. In the focused range, mass loss decreases quite homogeneously until a turning point when combustion reaction ends. This one changes quite a lot depending on the selected fuel, from nearly $500^{\circ} \mathrm{C}$ of PL, THI or $\mathrm{RH}$ to $800^{\circ} \mathrm{C}$ for $\mathrm{AS}, \mathrm{CC}$ or VO. It is interesting to have a high reaction-end temperature which permits to obtain fuel yields in a wider operation range.

\section{Conclusions}

In this work different biomass samples have been characterized by SEM, XRD, PSD, FRX and TG in order to establish which ones are the most desirable for combustion applications.

SEM images showed that the natural structure of harder biomass fuels (shells or husks) makes them easier to homogenise andhandle, than fibrous ones (wood or straw). The ashes obtained after $550{ }^{\circ} \mathrm{C}$ burning present a homogeneous finely-divided structure with presence of unburnt.

PSD study demonstrated that BP and PPLP generate a vast majority of thick ashes, while the selected brand of WP and AS have more than $35 \%$ of fine particles, increasing environmental and health risks with their use.

Deposition predictive equations, combined with FRX based ternary diagrams and experimental experience suggest that AS, PPLP, PL, PKS or VO present high deposition risks, decreasing the energy yield of the reaction. RH sample has huge corrosion risks due to its acidity which is confirmed by $\mathrm{Cl}$ presence measured by EDXA.

TG study showed that THI presented a low ignition point which has direct influence on auto-ignition and explosive atmospheres generation. AS, CC and VO present wider reaction ranges thank to their higher reaction-end temperature.

\section{Acknowledgements}


PSE-ARFRISOL, Ref. PS-120000-2005-1, is a scientific-technologic project qualified as Strategic by the 2004-07 Spanish National Plan of Research, Development and

277 Diffusion, co-financed by the European Regional Development Funds and the Spanish

Science and Education Ministry. We must acknowledge all members of the PSE-

ARFRISOL partnership for their cooperation.

We also wish to thank many companies such as Pellets Asturias, Factor Verde,

Molygrasa, Dibiosur, Enfosur, Acciona, Nutral Arrocerías Dorado, CarsanBio, Parque

Verde, Viñadecanes Vinos, la Cooperativa Agrícola de Cangas del Narcea, Vino de la

Tierra de Cangas, Gebio, Aragonesa Bioenergía and Cafés El Gallego for their disinterested collaboration supplying most of the necessary samples of the different biomasses.

This article is also greately indebted to MINECO for the economical facilities given to the project TRIBIONOR (CTQ2013-45155-R) that allows a continuity in this research field.

\section{References}

290

[1] Gil MV, Casal D, Pevida C, Pis JJ, Rubiera F. Thermal behaviour and

291 kinetics of coal/biomass blends during co-combustion. Bioresource Technol 2010; 101: 5601-8.

293

[2] Qian FP, Chyang CS, Huang KS, Tso J. Combustion and NO emission of

294 high nitrogen content biomass in a pilot-scale vortexing fluidized bed combustor. Bioresource Technol 2011; 102: 1892-8.

296 [3] Demirbas A. Importance of biomass energy sources for Turkey. Energ

297 Policy 2008; 36: 834-2.

298

[4] Sebastián F, García D, Rezeau A. Energías renovables-Energía de la biomasa (volumen I). Prensas Universitarias de Zaragoza. Zaragoza. 2010.

300 [5] Van Loo S, Koppejan J. The handbook of biomass combustion and co301 firing. Earthscan. London. 2010. 
[6] Fang X, Jia L. Experimental study on ash fusion characteristics of

303 biomass. Bioresource Technol 2012; 104: 769-4.

304 [7] Biagini E, Narducci P, Tognotti L. Size and structural characterization of 305 lignin-cellulosic fuels after the rapid devolatilization. Fuel 2008; 87: 177-6.

306 [8] Umamaheswaran K, Batra VS. Physico-chemical characterisation of 307 Indian biomass ashes. Fuel 2008; 87: 628-8.

308 [9] Xiao R, Chen X, Wang F, Yu G. The physicochemical properties of 309 different biomass ashes at different ashing temperature. Renew energ 2011; 310 36: 244-9.

311 [10] Nortey Yeboah NN, Shearer CR, Burns SE, Kurtis KE. Characterization 312 of biomass and high carbon content coal ash for productive reuse applications. 313 Fuel 2014; 116: 438-7

314 [11] Carrasco B, Cruz N, Terrados J, Corpas FA, Pérez L. An evaluation of 315 bottom ash from plant biomass as a replacement for cement in building 316 blocks. Fuel 2014; 118: 272-0

317 [12] Abraham R, George J, Thomas J, Yusuff KKM. Physicochemical 318 characterization and possible applications of the waste biomass ash from 319 oleoresin industries of India. Fuel 2013; 109: 366-2.

320 [13] Wang S, Miller A, Llamazos E, Fonseca F, Baxter L. Biomass fly ash in 321 concrete: Mixture proportioning and mechanical properties. Fuel 2008; 87: 365-1. [14] Bridgeman TG, Darvell LI, Jones JM, Williams PT, Fahmi R, Bridgewater AV et al. Influence of particle size on the analytical and chemical properties of two energy crops. Fuel 2007; 86: 60-72. [15] Mediavilla I, Fernández MJ, Esteban LS.Optimization of pelletisation and combustion in a boiler of $17.5 \mathrm{~kW}$ for vine shoots and industrial cork

328 residue. Fuel Process Technol 2009; 90: 621-8.

329 [16] Becidan M, Todorovic D, Skreiberg O, Khalil RA, Backman R, Goile F 330 et al. Ash related behaviour in staged and non-staged combustion of biomass 331 fuels and fuel mixtures. Biomass Bioenerg 2012; 41: 86-3. 
[17] Roy MM, Dutta A, Corscadden K. An experimental study of combustion

333 and emissions of biomass pellets in a prototype pellet furnace. App Energ 2013; 108: 298-7.

[18] Wang G, Silva RB, Azevedo JLT, Martins-Dias S, Costa M. Evaluation of the combustion behaviour and ash characteristics of biomass waste derived fuels, pine and coal in a drop tube furnace. Fuel 2014; 117: 809-24. [19] Vassilev SV, Baxter D, Andersen LK, Vassileva CG. An overview of the chemical composition of biomass. Fuel 2010; 89: 913-33. [20] Vassilev SV, Baxter D, Andersen LK, Vassileva CG. An overview of the composition and application of biomass ash. Part 1.Phase-mineral and chemical composition and classification. Fuel 2013; 105: 40-76. deposition during coal combustion under oxyfuel conditions. Fuel 2012; 92: $308-7$. effects during combustion of lignite/biomass blends in fluidized bed. Renew Energ 2009; 34: 2662-1.

[23] Fernández MJ, Carrasco JE. Comparing methods for predicting the sintering of biomass ash in combustion. Fuel 2005; 84: 1893-0. [24] Vassilev SV, Baxter D, Andersen LK, Vassileva CG, Morgan TJ. An overview of the organic and inorganic phase composition of biomass.Fuel2012; 94: 1-33.

[25] Magdziarz A, Wilk M. Thermogravimetric study of biomass, sewage sludge and coal combustion. Energ Convers Manage 2013; 75:425-0. [26] Sarkar P, Sahu SG, Mukherjee A, Kumar M, Adak AK, Chakraborty N et

357 al. Co-combustion studies for potential application of sawdust or its low 358 temperature char as co-fuel with coal. App Therm Eng 2014; 63: 616-3.

359 [27] VersanKok M, Özgür E. Thermal analysis and kinetics of biomass 360 samples. Fuel Process Technol 2013; 106: 739-3 
361 [28] García R, Pizarro C, Lavín AG, Bueno JL. Biomass proximate analysis

362 using thermogravimetry. Bioresource Technol 2013; 139: 1-4.

363 [29] Ávila C, Pang CH, Wu T, Lester E. Morphology and reactivity of char 364 biomass particles. Bioresource Technol 2011; 102: 5237-3.

365 [30] Fernández MJ, Carrasco JE. Concentration of elements in woody and 366 herbaceous biomass as a function of the dry ashing temperature. Fuel 2006; 367 85: 1273-9.

368 [31] Thyrel M, Samuelsson R, Finell M, Lestander TA. Critical ash elements 369 in biorefinery feedstock determined by X-ray spectroscopy. App Energ 2013; 370 102: 1288-4.

371 [32] García-Maraver A, Terron LC, Ramos-Ridao A, Zamorano M. Effects of 372 mineral contamination on the ash content of olive tree residual biomass.

373 Biosystems Eng 2014; 118: 167-3.

374 [33] García R, Pizarro C, Lavín AG, Bueno JL. Characterization of Spanish 375 biomass wastes for energy use. Bioresource Technol 2012; 103: 249-8.

376 [34] Tortosa-Masiá AA, Buhre BJP, Gupta RP, Wall TF. Characterising ash 377 of biomass and waste. Fuel ProcessTechnol2007; 88: 1071-1.

378 [35] Grammelis P, Skodras G, Kakaras E. Effects of biomass co-firing with 379 coal on ash properties. Part I: Characterisation and PSD. Fuel 2006; 85: 23103805. 
Table 1

Tested fuels analytical values.

\begin{tabular}{llllllllllll}
\hline \multirow{2}{*}{ Sample } & \multicolumn{9}{l}{ Proximate analysis } & \multicolumn{1}{c}{ Ultimate analysis } & \multicolumn{2}{l}{ HHV } & Ash & VM & FC & N & C & S & H & O & C/O \\
AS & 8.68 & 2.2 & 82 & 15.8 & 18275 & 0.3 & 46.35 & 0.22 & 5.67 & 47.46 & 0.98 \\
BP & 12.5 & 9 & 76 & 15 & 15095 & 1.19 & 38.94 & 0.51 & 5.23 & 54.13 & 0.72 \\
BRI & 5.84 & 0.8 & 85 & 14.2 & 18498 & 1.24 & 46.74 & 0.1 & 6.39 & 45.53 & 1.03 \\
CC & 5.29 & 5.9 & 26 & 68.1 & 29712 & 0.65 & 79.34 & 0.3 & 2.74 & 16.97 & 4.68 \\
CH & 9.6 & 5.8 & 76.2 & 18 & 18236 & 2.53 & 45.06 & 0.48 & 6.42 & 45.51 & 0.99 \\
OS & 11 & 1.4 & 78.3 & 20.3 & 17884 & 1.781 & 46.55 & 0.11 & 6.33 & 45.229 & 1.03 \\
OTP & 8.7 & 13 & 78 & 9 & 17342 & 1.47 & 45.36 & 0.28 & 5.47 & 47.42 & 0.96 \\
PPLP & 8.2 & 3.2 & 75 & 21.8 & 18147 & 0.4 & 42.26 & 0.27 & 4.81 & 52.26 & 0.81 \\
PKS & 9.14 & 1.3 & 80 & 18.7 & 18633 & 0.27 & 47.65 & 0.11 & 6.33 & 45.2 & 1.05 \\
PL & 8.33 & 2.7 & 77.6 & 19.7 & 18893 & 0.31 & 47.91 & 0.6 & 4.9 & 46.28 & 1.04 \\
RH & 7.27 & 13.7 & 74 & 12.3 & 15899 & 0.21 & 26.69 & 0.17 & 2.88 & 70.05 & 0.38 \\
S & 6.1 & 17 & 62 & 21 & 11872 & 0.73 & 37.89 & 0.21 & 5.94 & 55.23 & 0.69 \\
SP & 7.3 & 9.8 & 79 & 11.2 & 16584 & 0.56 & 47.89 & 0.17 & 5.51 & 45.87 & 1.04 \\
TH & 11.6 & 0.2 & 80.67 & 19.13 & 17747 & 0.48 & 43.89 & 0.28 & 6.46 & 48.89 & 0.90 \\
VO & 9.5 & 12.7 & 79 & 8.3 & 17742 & 1.91 & 44.15 & 0.58 & 5.31 & 48.05 & 0.92 \\
VSC & 22 & 9.7 & 66 & 24.3 & 14631 & 0.61 & 40.15 & 0.31 & 5.02 & 53.91 & 0.74 \\
WC & 25.6 & 1.5 & 68.6 & 29.9 & 15162 & 0.13 & 42.2 & 0.27 & 5.51 & 51.89 & 0.81 \\
WP & 7.7 & 1.3 & 82 & 16.7 & 18218 & 0.6 & 46.79 & 0.32 & 6.13 & 46.16 & 1.01 \\
\hline
\end{tabular}

$M$. ash. $V M$ and $F C$ respectively mean moisture Ash, volatile matter and fixed carbon. Measured in mass percentage. $H H V$ is the higher heating value measured in J/g. C. N. $H . O$ and $S$ are the mass percentage of carbon, nitrogen, hydrogen, oxygen and sulphur. 


\section{Table 2}

Review of deposition-predictive indexes.

\section{Method}

Base/acid ratio

$[9,14,21,22]$

Silicon/alumina ratio $[9,14,22]$

Iron/calcium ratio $[14,22]$

Slagging index $[14,22]$

Slag viscosity index $[9,14]$

Chlorine content [14]

Fouling index I

Fouling index II [21]

Alkali index [14]

I parameter [23]

Total alkali content $[14,22]$

$\mathrm{H}$ fouling index [9]

$$
\begin{aligned}
& H=R_{b} / a \cdot \mathrm{Na}_{2} \mathrm{O} \text { if } \frac{\mathrm{Fe}_{2} \mathrm{O}_{3}}{\mathrm{CaO}+\mathrm{MgO}}>1 \\
& \mathrm{H}=\mathrm{Na}_{2} \mathrm{O} \text { if } \frac{\mathrm{Fe}_{2} \mathrm{O}_{3}}{\mathrm{CaO}+\mathrm{MgO}}<1 \text { and } \mathrm{CaO}+\mathrm{MgO}>2
\end{aligned}
$$

Fusion temp index [18]

\section{Formulae}

$$
R_{b / a}=\frac{\mathrm{Fe}_{2} \mathrm{O}_{3}+\mathrm{CaO}+\mathrm{MgO}+\mathrm{K}_{2} \mathrm{O}+\mathrm{Na}_{2} \mathrm{O}}{\mathrm{SiO}_{2}+\mathrm{TiO}_{2}+\mathrm{Al}_{2} \mathrm{O}_{3}}
$$

$\mathrm{P}_{2} \mathrm{O}_{5}$ may be also added as a Basic oxide [34]

$$
\begin{aligned}
& S /_{A}=\frac{\mathrm{SiO}_{2}}{\mathrm{Al}_{2} \mathrm{O}_{3}} \\
& I /_{C}=\frac{\mathrm{Fe}_{2} \mathrm{O}_{3}}{\mathrm{CaO}} \\
& R_{S}=R_{b / a} \cdot S
\end{aligned}
$$

$$
S_{R}=\frac{\mathrm{SiO}_{2}}{\mathrm{SiO}_{2}+\mathrm{Fe}_{2} \mathrm{O}_{3}+\mathrm{CaO}+\mathrm{MgO}} \cdot 100
$$

Weight percentage of $\mathrm{Cl}$. in an "as received" fuel sample

$$
F_{u}=R_{b / a} \cdot\left(K_{2} \mathrm{O}+\mathrm{Na}_{2} \mathrm{O}\right)
$$

$$
F=\frac{\mathrm{K}_{2} \mathrm{O}+\mathrm{Na}_{2} \mathrm{O}}{2 \cdot \mathrm{S}+\mathrm{Cl}}
$$

$$
I A=\frac{1}{H H V} \cdot A s h \cdot\left(K_{2} \mathrm{O}+\mathrm{Na}_{2} \mathrm{O}\right)
$$

$$
I=\frac{\mathrm{CaO}+\mathrm{MgO}}{\mathrm{K}_{2} \mathrm{O}+\mathrm{Na}_{2} \mathrm{O}}
$$

$$
\mathrm{TA}=\left(\mathrm{K}_{2} \mathrm{O}+\mathrm{Na}_{2} \mathrm{O}\right)
$$

$$
F=\frac{\mathrm{SiO}_{2}+\mathrm{K}_{2} \mathrm{O}+\mathrm{P}_{2} \mathrm{O}_{5}}{\mathrm{CaO}+\mathrm{MgO}}
$$

\section{Deposition criteria}

$<0.5 \rightarrow$ low

$0.5-1 \rightarrow$ medium

$>1 \rightarrow$ high

$<0.31$ or $>3 \rightarrow$ low

$0.31-3 \rightarrow$ high

$<0.31$ or $>3 \rightarrow$ low

$0.31-3 \rightarrow$ high

$<0.6 \rightarrow$ low

$0.6-2 \rightarrow$ medium

$>2 \rightarrow$ high

$>78 \rightarrow$ low

66.1-78 $\rightarrow$ medium

$<66.1 \rightarrow$ high

$<0.2 \rightarrow$ low

$0.2-0.3 \rightarrow$ medium

$0.3-0.5 \rightarrow$ high

$>0.5 \rightarrow$ really high

$<0.6 \rightarrow$ low

$0.6-40 \rightarrow$ high

$>40 \rightarrow$ extremely high

Higher as higher $\mathrm{F}$

$>0.17 \rightarrow$ probably

fouling

$>0.34 \rightarrow$ sure

$>2$ no sinter

$<0.3 \rightarrow$ low

0.3-0.4 $\rightarrow$ medium

$>0.4 \rightarrow$ high

$<3 \rightarrow$ medium

$>3 \rightarrow$ high

Higher tendency as higher $F$ value

Each element/oxide symbol means its weight percentage of obtained from elemental analysis (S), EDXA $(\mathrm{Cl})$ or XRF (oxides). $H H V$ is the higher heating value measured in $\mathrm{GJ} / \mathrm{kg}$ and ash the ash mass percentage of the measured sample. 
Table 3

X-Ray fluorescence data.

\begin{tabular}{|c|c|c|c|c|c|c|c|c|c|c|c|c|}
\hline & \multicolumn{10}{|c|}{ XRF data } & \multicolumn{2}{|c|}{ Equations } \\
\hline & $\mathrm{SiO}_{2}$ & $\mathrm{Al}_{2} \mathrm{O}_{3}$ & $\mathrm{Fe}_{2} \mathrm{O}_{3}$ & MnO & MgO & $\mathrm{CaO}$ & $\mathrm{Na}_{2} \mathrm{O}$ & $\mathbf{K}_{2} \mathrm{O}$ & $\mathrm{TiO}_{2}$ & $\mathbf{P}_{2} \mathrm{O}_{5}$ & $\mathbf{R}_{\mathrm{b} / \mathbf{a}}$ & $\mathbf{F}_{\mathbf{u}}$ \\
\hline AS & 31.0 & 4.4 & 1.2 & 0.1 & 6.3 & 25.7 & 1.4 & 25.8 & 0.1 & 3.9 & 1.7 & 46.4 \\
\hline BP & 42.3 & 5.2 & 1.5 & 0.1 & 6.3 & 35.1 & 1.2 & 4.2 & 0.3 & 3.8 & 1.0 & 5.4 \\
\hline BRI & 24.5 & 9.6 & 1.8 & 1.3 & 7.5 & 39.2 & 1.9 & 10.1 & 1.7 & 2.5 & 1.7 & 20.2 \\
\hline $\mathrm{CC}$ & 15.9 & 3.1 & 2.2 & 0.4 & 7.3 & 45.0 & 2.7 & 15.4 & 0.2 & 7.8 & 3.8 & 68.1 \\
\hline CH & 5.3 & 1.5 & 1.9 & 0.4 & 14.4 & 59.4 & 1.5 & 11.5 & 0.1 & 3.9 & 12.8 & 166.8 \\
\hline OS & 26.6 & 6.2 & 3.1 & 0.1 & 11.7 & 37.0 & 0.9 & 11.0 & 0.4 & 3.0 & 1.9 & 23.0 \\
\hline OTP & 50.1 & 3.9 & 1.6 & 0.1 & 2.6 & 33.5 & 0.5 & 5.5 & 0.4 & 1.9 & 0.8 & 4.8 \\
\hline PPLP & 49.2 & 5.6 & 1.1 & 0.1 & 4.9 & 6.5 & 1.3 & 27.1 & 0.1 & 4.1 & 0.7 & 21.2 \\
\hline PL & 18.1 & 4.7 & 6.3 & 0.3 & 14.2 & 11.5 & 1.9 & 35.3 & 0.1 & 7.7 & 3.0 & 112.3 \\
\hline PKS & 51.3 & 4.1 & 2.9 & 0.1 & 4.8 & 7.5 & 1.4 & 24.6 & 0.1 & 3.3 & 0.7 & 19.2 \\
\hline RH & 88.2 & 1.3 & 0.4 & 0.3 & 1.1 & 1.8 & 0.4 & 4.9 & 0.0 & 1.7 & 0.1 & 0.5 \\
\hline $\mathbf{S}$ & 53.9 & 7.2 & 3.3 & 0.1 & 1.9 & 29.5 & 0.7 & 2.2 & 0.5 & 0.8 & 0.6 & 1.7 \\
\hline SP & 53.5 & 1.6 & 0.6 & 0.1 & 2.3 & 20.6 & 0.9 & 17.8 & 0.1 & 2.5 & 0.8 & 14.3 \\
\hline THI & 5.5 & 1.2 & 1.5 & 0.1 & 10.5 & 69.3 & 0.9 & 5.0 & 0.1 & 5.8 & 12.6 & 73.8 \\
\hline VO & 23.9 & 4.1 & 1.3 & 0.1 & 9.2 & 15.9 & 1.7 & 32.9 & 0.1 & 10.8 & 2.2 & 75.5 \\
\hline VSC & 6.6 & 1.0 & 0.6 & 0.7 & 14.7 & 53.6 & 0.7 & 9.5 & 0.1 & 12.7 & 10.3 & 105.4 \\
\hline WC & 28.8 & 5.1 & 7.4 & 0.7 & 5.2 & 35.5 & 1.8 & 5.7 & 6.5 & 3.4 & 1.4 & 10.2 \\
\hline WP & 21.3 & 4.8 & 3.7 & 0.4 & 8.8 & 28.5 & 1.7 & 20.9 & 1.8 & 8.1 & 2.3 & 51.8 \\
\hline
\end{tabular}


Table 4 - Characteristic points of TGA analysis.

\begin{tabular}{llll}
\hline Sample & $\mathbf{T}_{\text {ignition }}\left({ }^{\mathbf{0}} \mathbf{C}\right)$ & $\mathbf{T}_{\text {peak }}\left({ }^{\mathbf{0}} \mathbf{C}\right)$ & $\mathbf{T}_{\text {reaction-end }}\left({ }^{\mathbf{0}} \mathbf{C}\right)$ \\
AS & 171 & 296 & 791 \\
BP & 183 & 232 & 750 \\
BRI & 169 & 340 & 611 \\
CC & 233 & 478 & 775 \\
CH & 170 & 322 & 550 \\
OS & 195 & 289 & 609 \\
OTP & 180 & 325 & 548 \\
PPLP & 178 & 331 & 697 \\
PL & 183 & 318 & 506 \\
PKS & 194 & 333 & 716 \\
RH & 188 & 319 & 521 \\
S & 195 & 331 & 525 \\
SP & 170 & 287 & 619 \\
THI & 130 & 339 & 531 \\
VO & 182 & 269 & 804 \\
VSC & 195 & 324 & 550 \\
WC & 212 & 340 & 517 \\
WP & 200 & 332 & 631 \\
\hline
\end{tabular}




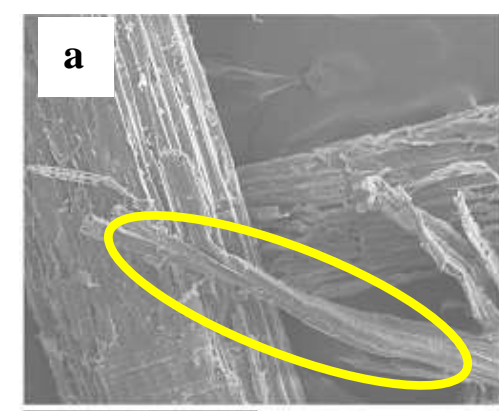

$800 \mu \mathrm{m}$

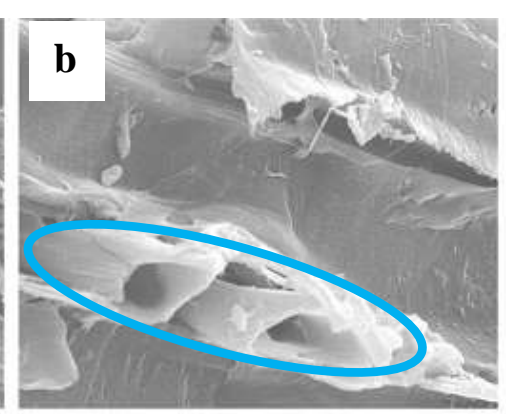

$20 \mu \mathrm{m}$

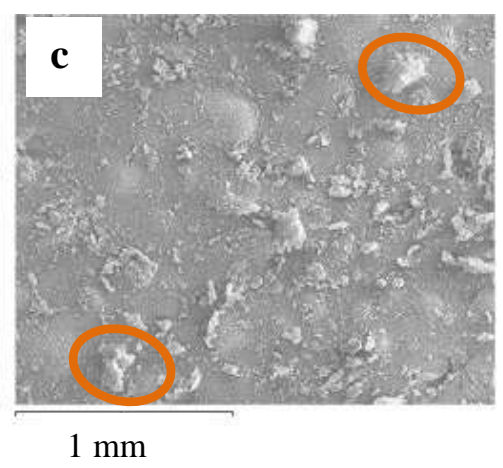

$1 \mathrm{~mm}$

Figure 1. Wood chips SEM captures at room temperature (a x65 magnifications and b x2000) and after $550^{\circ} \mathrm{C}$ burning (c x50 magnifications). 


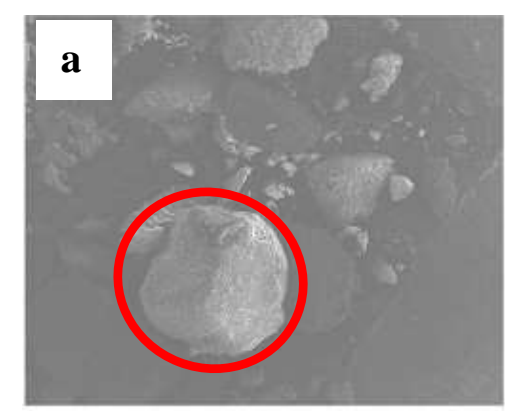

$2 \mathrm{~mm}$

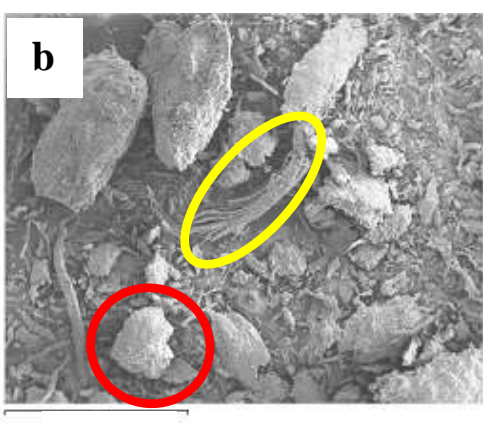

$1 \mathrm{~mm}$

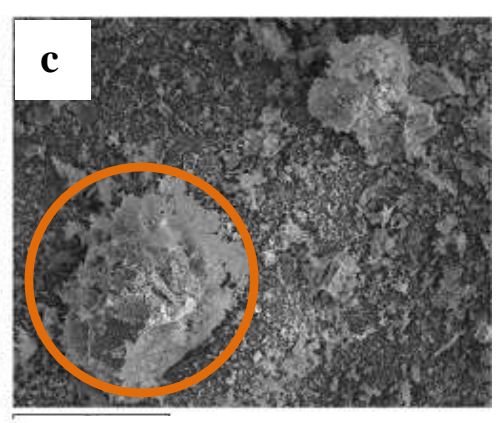

$10 \mu \mathrm{m}$

Figure 2. Pine kernel shell (a room temperature x20) and pine and pine-apple leaf pellets' (b room temperature $\mathrm{x} 40$ and c after $550^{\circ} \mathrm{C}$ burning $\mathrm{x} 350$ ) SEM captures 


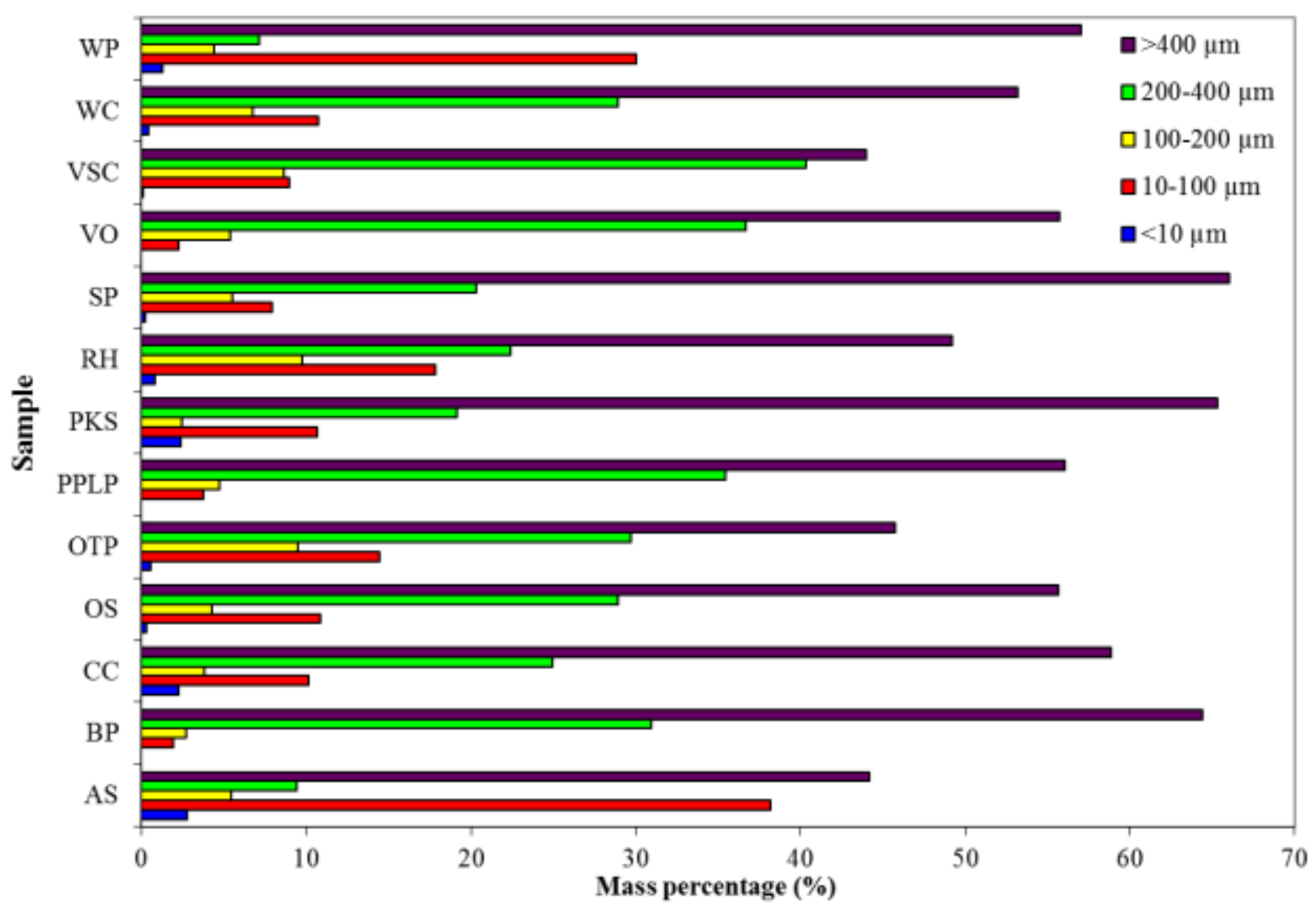

Figure 3. Particle size distribution of the selected biomass samples. 


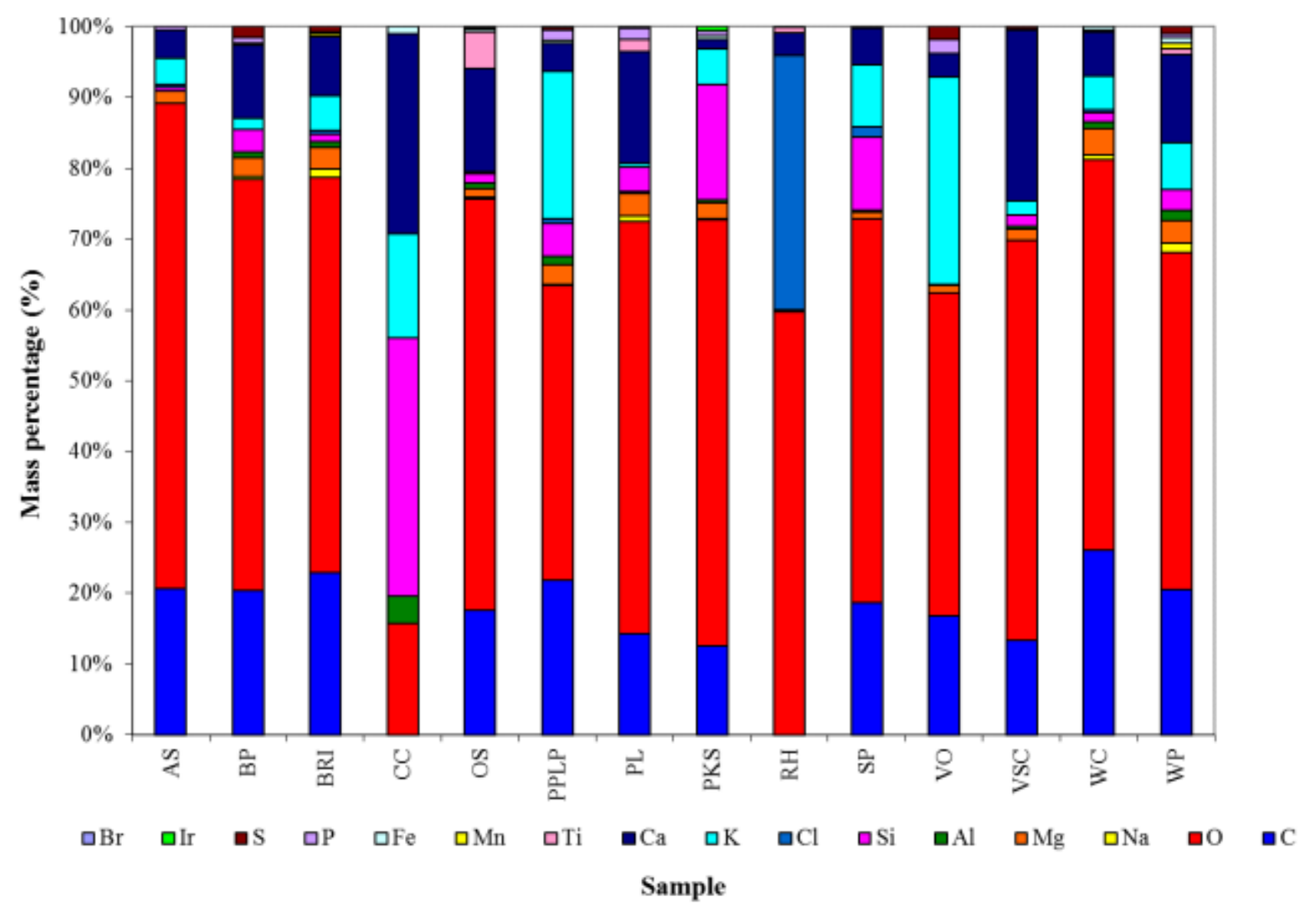

Figure 4. Results obtained from EDXA analysis. 


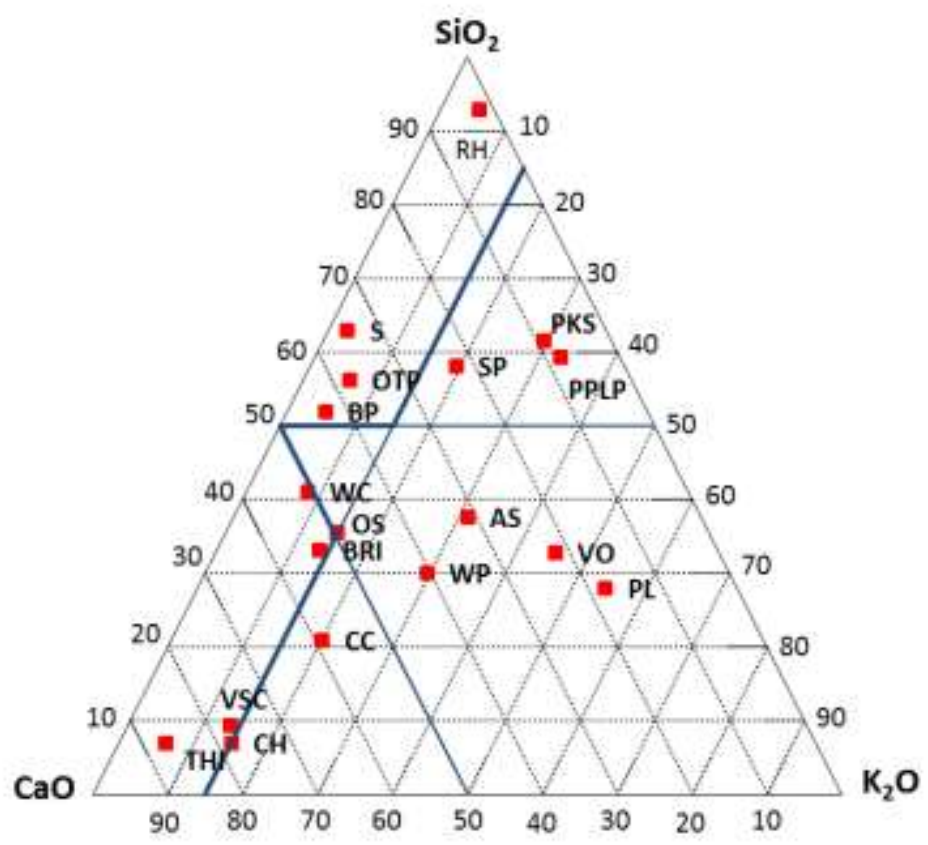

Figure 5. $\mathrm{SiO}_{2}-\mathrm{CaO}-\mathrm{K}_{2} \mathrm{O}$ ternary diagram. 


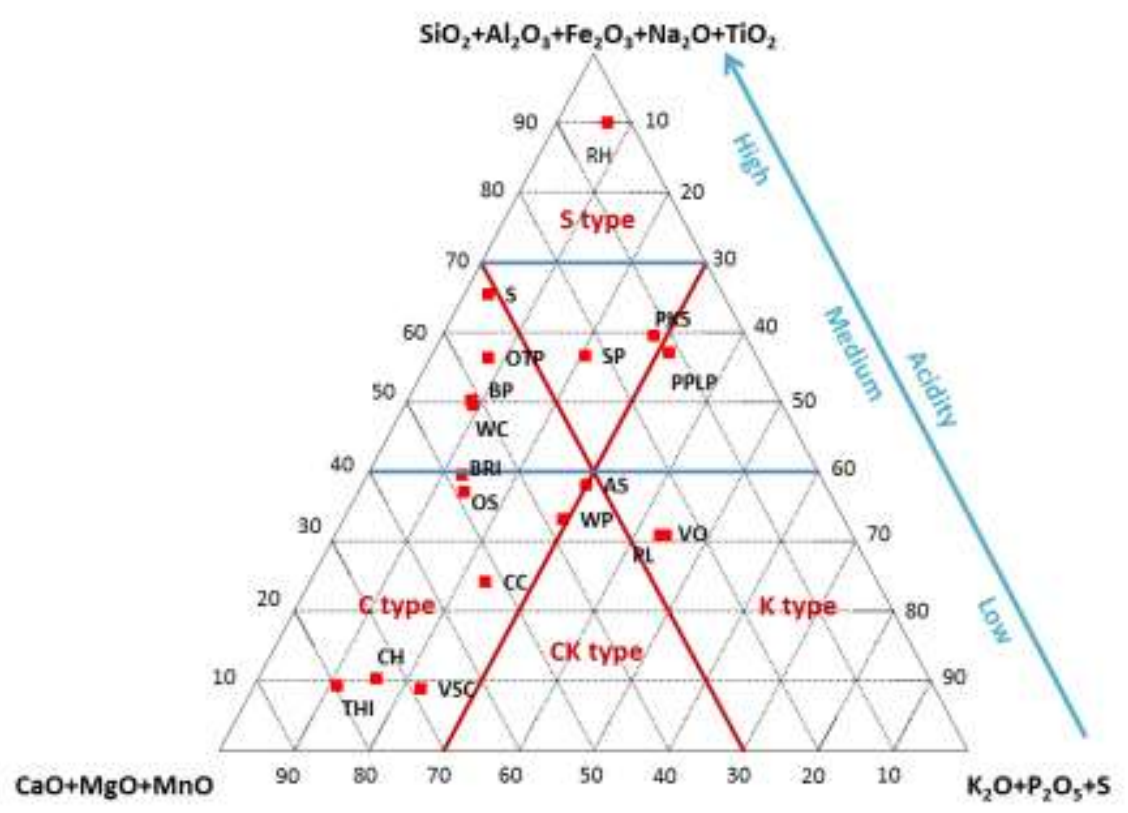

Figure 6. $\mathrm{SiO}_{2}+\mathrm{Al}_{2} \mathrm{O}_{3}+\mathrm{Fe}_{2} \mathrm{O}_{3}-+\mathrm{Na} 2 \mathrm{O}+\mathrm{TiO}_{2}-\mathrm{CaO}+\mathrm{MgO}+\mathrm{MnO}-\mathrm{K}_{2} \mathrm{O}+\mathrm{P}_{2} \mathrm{O}_{5}+\mathrm{S}$ ternary diagram. 


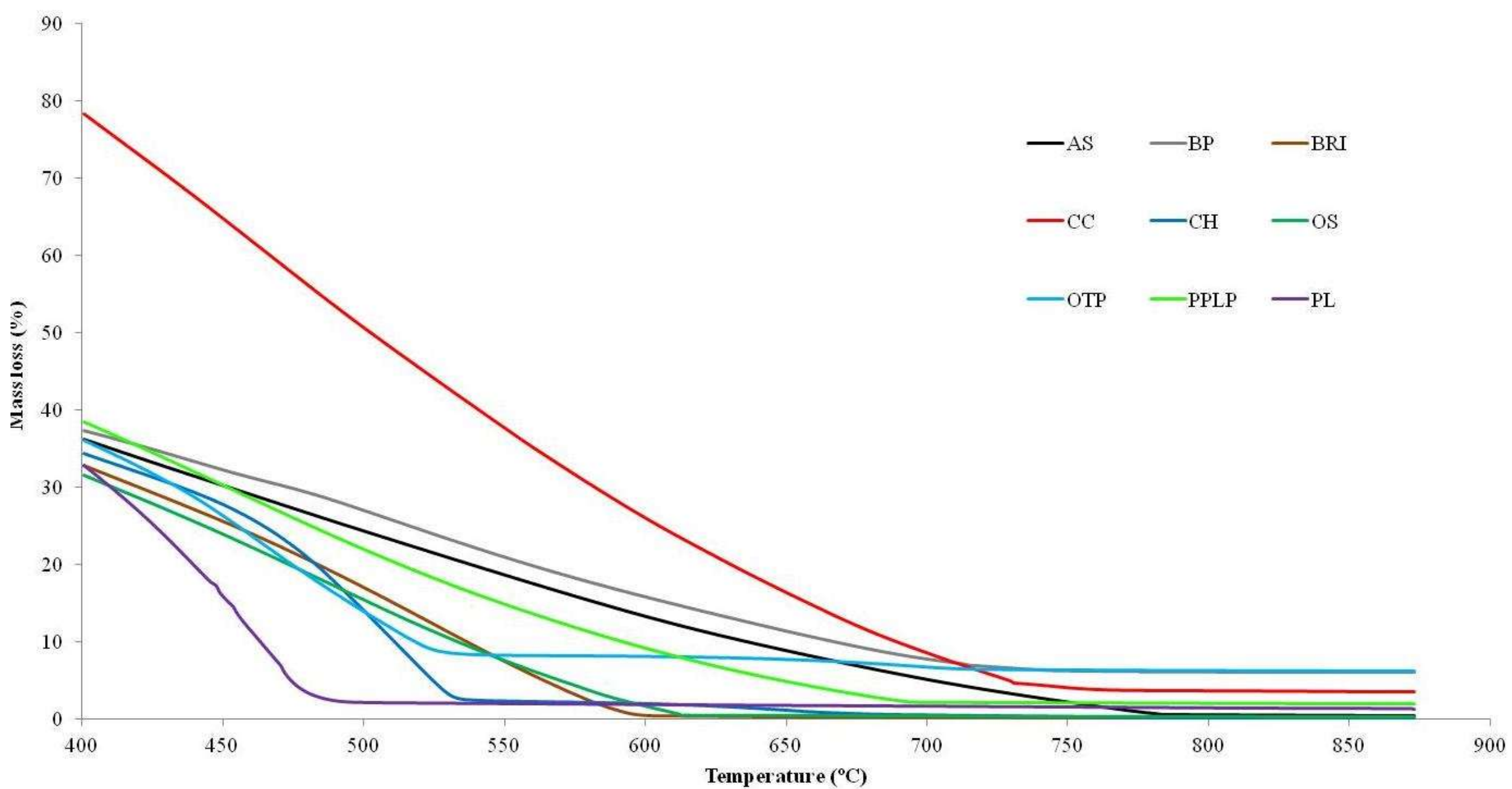

Figure 7. TGA profiles for several biomass samples from $400^{\circ} \mathrm{C}$ (I). 


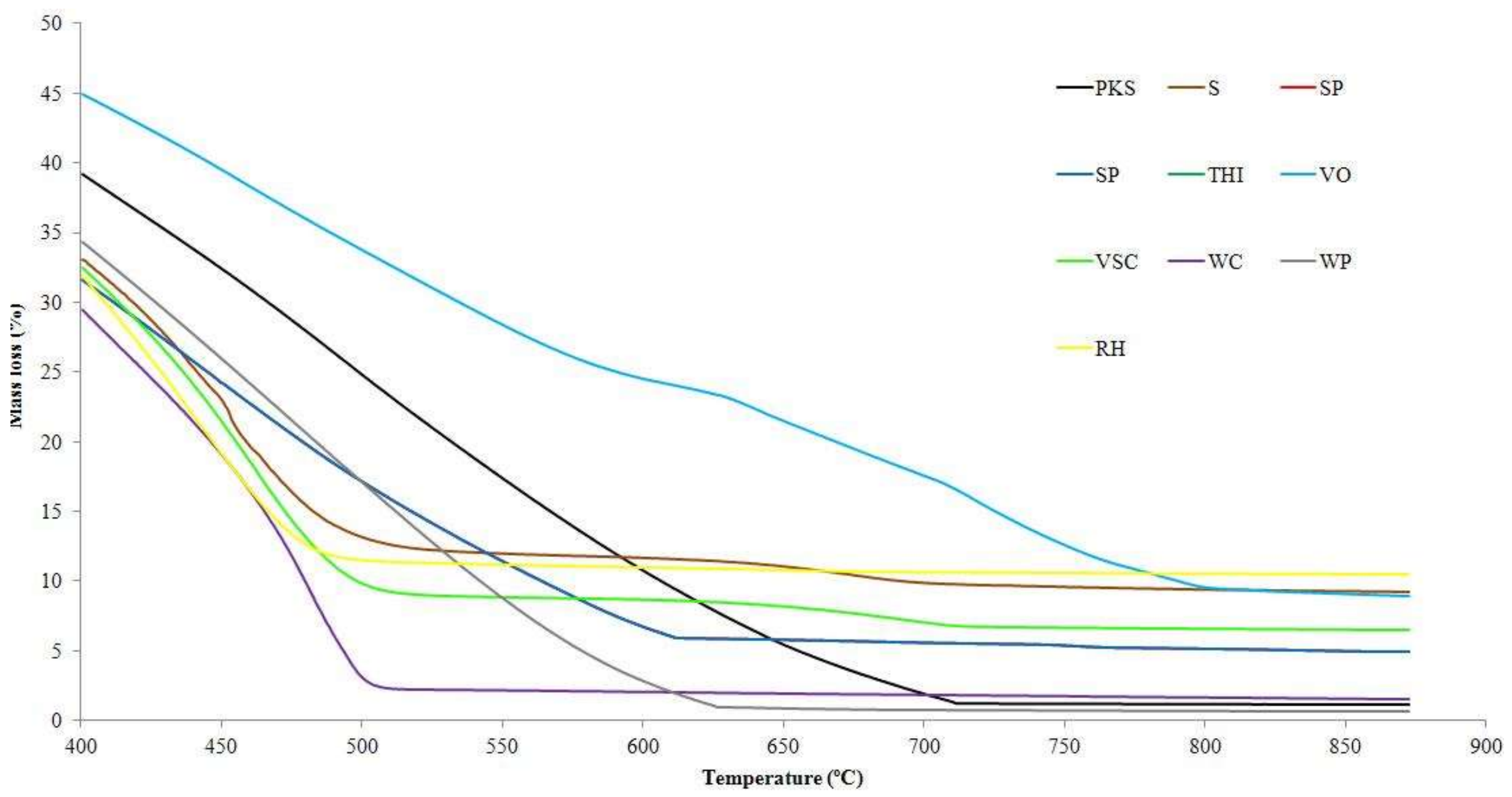

Figure 8. TGA profiles for several biomass samples from $400^{\circ} \mathrm{C}$ (II). 